\title{
Overcoming statistical machine translation limitations: error analysis and proposed solutions for the Catalan-Spanish language pair
}

\author{
Mireia Farrús $\cdot$ Marta R. Costa-jussà $\cdot$ José B. Mariño • \\ Marc Poch • Adolfo Hernández $\cdot$ Carlos Henríquez $\cdot$ José A. R. Fonollosa
}

Published online: 20 February 2011

(C) Springer Science+Business Media B.V. 2011

\begin{abstract}
This work aims to improve an N-gram-based statistical machine translation system between the Catalan and Spanish languages, trained with an aligned SpanishCatalan parallel corpus consisting of 1.7 million sentences taken from El Periódico
\end{abstract}

M. Farrús $(\bowtie) \cdot$ M. R. Costa-jussà · J. B. Mariño · M. Poch · A. Hernández ·

C. Henríquez · J. A. R. Fonollosa

TALP Research Center, Department of Signal Theory and Communications,

Universitat Politècnica de Catalunya, C/Jordi Girona 1-3, 08034 Barcelona, Spain

e-mail: mireia.farrus@upc.edu

Present Address:

M. Farrús

Office of Learning Technologies, Universitat Oberta de Catalunya,

Av. Tibidabo, 47, 08035 Barcelona, Spain

e-mail:mfarrusc@uoc.edu

J. B. Mariño

e-mail: jose.marino@upc.edu

M. Poch

e-mail: marc.poch@upc.edu

A. Hernández

e-mail: adolfo.hernandez@upc.edu

C. Henríquez

e-mail: carlos.henriquez@upc.edu

J. A. R. Fonollosa

e-mail: jose.fonollosa@upc.edu

M. R. Costa-jussà

Voice and Language Department, Barcelona Media Innovation Center,

Av Diagonal 177, 9th Floor, 08018 Barcelona, Spain

e-mail: marta.ruiz@barcelonamedia.org

Present Address:

M. Poch

Universitat Pompeu Fabra, Roc Boronat, 138, 08018 Barcelona, Spain

e-mail: marc.pochriera@upf.edu 
newspaper. Starting from a linguistic error analysis above this baseline system, orthographic, morphological, lexical, semantic and syntactic problems are approached using a set of techniques. The proposed solutions include the development and application of additional statistical techniques, text pre- and post-processing tasks, and rules based on the use of grammatical categories, as well as lexical categorization. The performance of the improved system is clearly increased, as is shown in both human and automatic evaluations of the system, with a gain of about 1.1 points BLEU observed in the Spanish-to-Catalan direction of translation, and a gain of about 0.5 points in the reverse direction. The final system is freely available online as a linguistic resource.

Keywords Statistical machine translation - N-gram-based translation · Linguistic knowledge · Grammatical categories

\section{Introduction}

Currently, Statistical Machine Translation (SMT) is one of the most popular Machine Translation paradigms. The SMT approach allows programmers to build a translator with open-source tools as long as a parallel corpus is available. If the languages involved in the translation belong to the same language family, the translation quality can be surprisingly high. Furthermore, one of the most attractive reasons to build a statistical system instead of a standard rule-based system is that little human effort is required.

Theoretically, when using SMT, no linguistic knowledge is required. In practice, once the system is built, linguistic knowledge becomes necessary to achieve perfect translations at all grammatical levels, as it has been seen in recent works (Niessen and Ney 2000; Popović and Ney 2004, 2006). In fact, the main question that arose at the beginning of this work was: which are the steps to follow when the main goal is to improve an already high-quality statistical translation?

We consider a translation system to be of high quality when almost no postediting is needed. Actually, this is a relatively unusual situation in the field of MT, where most systems offer translations that have to be post-edited. This study is devoted to developing translation at this stage in the Catalan-Spanish pair in both directions. Therefore, the main objective here is to obtain a translation system that does not require any post-editing.

Starting with a high-quality baseline SMT system, a human analysis of the output is performed, which is then used to make further improvements via the introduction of statistical techniques and linguistic rules. One main consideration is the methodology of the study. Our study methodology is based primarily on the detection and classification of systematic errors, followed by the proposal of suitable solutions. When possible, solutions will be statistical; otherwise, they will be linguistic.

This paper is organized as follows. First, a brief description of the Catalan and Spanish languages and the N-gram-based statistical translation system used as the baseline system are presented. Next, we report the error analysis and classification performed on the system described in the previous section, and the proposed solutions to solve these errors. Then, the improved system is carefully evaluated with respect to the baseline system and, finally, conclusions and future work are summarized in last section. 


\section{Catalan and Spanish languages}

Catalan and Spanish belong to the family of Romanic languages, also referred to as Romance or Latin languages. This family also includes other languages, such as French, Italian, Portuguese and Romanian, as it is comprised of all the languages descending from Vulgar Latin, which is, in turn, a branch of the Indo-European language family. Although the evolution of Latin into such Romanic languages occurred at all levels (phonological, morphological, lexical, etc.), the main characteristic of these languages is found at the syntactic level, with the loss of the declension system, which has led to a generalized use of SVO sentence structures with a large amount of prepositions.

The Catalan language is spoken by more than 9 million people distributed among Catalonia, the Valencian Community, the Balearic Islands, Andorra, and part of Aragon, Sardinia, Southern France and Murcia. On the other hand, Spanish is spoken by more than 400 million people as a native language in Spain and several countries in America, Asia and Africa. Spanish is the second most spoken language in the world after Mandarin Chinese.

The main sociolinguistic characteristic of Catalan is the fact that it is found in a socially bilingual environment in all the regions where it is spoken: with Spanish in Spain (Catalonia, Aragon, Murcia) and Andorra, with French in South France and Andorra, and with Italian in Sardinia. This fact highlights the need for bilingual communication in all of these regions, where helping systems and resources have become increasingly popular and necessary.

\section{N-gram-based statistical translation system}

The translation system used in the current study — called N-II ${ }^{1}$-is an N-gram-based SMT system developed at the Universitat Politècnica de Catalunya (UPC), trained with the aligned Spanish-Catalan parallel corpus taken from El Periódico newspaper. This corpus contains 1.7 million sentences, a rich vocabulary and nearly $4.24 \cdot 10^{7}$ words in average, as shown in Table 1.

An N-gram-based SMT system regards translation as a stochastic process. We are given a source string $s_{1}^{J}=s_{1} \ldots s_{j} \ldots s_{J}$, which is to be translated into a target string $t_{1}^{I}=t_{1} \ldots t_{i} \ldots t_{I}$. Among all possible target strings, we will choose the string with the highest probability:

Table 1 El Periódico corpus statistics

\begin{tabular}{lrr}
\hline & Catalan & Spanish \\
\hline Sentences & $1.7 \mathrm{M}$ & $1.7 \mathrm{M}$ \\
Words & $41.5 \mathrm{M}$ & $43.3 \mathrm{M}$ \\
Vocabulary & $397.4 \mathrm{k}$ & $390.2 \mathrm{k}$ \\
\hline
\end{tabular}

${ }^{1}$ http://www.n-ii.org. 


$$
\tilde{t}_{1}^{I}=\underset{t_{1}^{I}}{\arg \max } P\left(t_{1}^{I} \mid s_{1}^{J}\right)
$$

The argmax operation denotes the search problem, i.e. the generation of the output sentence in the target language. In recent systems, such an approach will assume a general maximum entropy in which a log-linear combination of multiplefeature functions is implemented (Och 2003). This approach tends to maximize a linear combination of feature functions:

$$
\tilde{t}=\underset{t}{\arg \max }\left\{\sum_{m=1}^{M} \lambda_{m} h_{m}(t, s)\right\}
$$

\subsection{Translation feature functions}

The main feature function is the $\mathrm{N}$-gram-based translation model, which is trained with bilingual $n$-grams. This model constitutes a language model of a particular $b i$ language composed of bilingual units (translation units) which are referred to as tuples. In this way, translation model probabilities at the sentence level are approximated by using $n$-grams of tuples, such as described by the following equation:

$$
\hat{t}_{1}^{I}=\underset{t_{1}^{I}}{\arg \max }\left\{p\left(s_{1}^{J}, t_{1}^{J}\right)\right\}=\ldots=\underset{t_{1}^{I}}{\arg \max }\left\{\prod_{n=1}^{N} p\left((s, t)_{n} \mid(s, t)_{n-x+1}, \ldots,(s, t)_{n-1}\right)\right\}
$$

where the $n$-th tuple of a sentence pair is referred to as $(s, t)_{n}$. As any standard $n$-gram language model, the bilingual translation model is estimated over a training corpus composed of sentences in the language being modeled. In this case, we consider sentences in the bilanguage mentioned previously.

The N-gram-based approach is monotonic in that its model is based on the sequential order of tuples during training. Therefore, the baseline system may be especially appropriate for pairs of languages with relatively similar word order schemes.

Tuples are extracted from a word-to-word aligned corpus in such a manner that a unique segmentation of the bilingual corpus is achieved. Although in principle, any Viterbi alignment should allow for tuple extraction, the resulting tuple vocabulary strongly depends on the particular alignment set considered. According to our experience (Mariño et al. 2006), in some specific tasks the best performance is achieved when the union of the source-to-target and target-to-source alignment sets is used for tuple extraction.

In this way, which is different from other implementations, where one-to-one (Bangalore and Riccardi 2000) or one-to-many (Casacuberta and Vidal 2004) alignments are used, tuples are extracted from many-to-many alignments. This implementation produces a monotonic segmentation of bilingual sentence pairs, which allows for the simultaneous capture of contextual information and the 


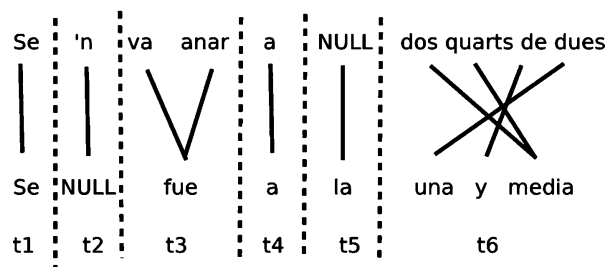

Illustration 1 Example of tuple extraction in the sentence he left at half past one

reordering of information into the bilingual translation unit structures. This segmentation also allows the estimation of the $n$-gram probabilities. To guarantee a unique segmentation of the corpus, tuple extraction is performed according to the following constraints:

- a monotonic segmentation of each bilingual sentence pair is produced,

- no word inside the tuple is aligned to words outside the tuple, and

- no smaller tuples can be extracted without violating the previous constraints.

Illustration 1 presents a simple example showing the unique tuple segmentation for a given pair of sentences, which mean he left at half-past one.

Two important observations from Illustration 1, related to null and embedded words, must be considered:

NULL: In some cases, such as tuple 2, there are possible occurrences of tuples containing unaligned elements in its target side. This kind of tuple should be handled in an alternative manner in order for the system to be able to provide appropriate translations for such unaligned elements. The problem of how to handle this kind of situation has been discussed in detail (Mariño et al. 2006). In short, since no NULL is actually expected to occur in translation inputs, this type of tuple is not allowed. Any target word that is linked to NULL is attached either to the word that precedes or to the word that follows it. To determine this, we use the IBM-1 probabilities. More specifically, the IBM-1 lexical parameters (Brown et al. 1993) are used for computing the translation probabilities of two possible new tuples: the one that results when the null-aligned-word is attached to the previous word, and the one that results when it is attached to the following one. Then, the attachment direction is selected according to the tuple with the highest translation probability.

Embedded words: Often, a large number of single-word translation probabilities are left out of the model. This happens for words that are always embedded in tuples containing two or more words. Consider for example the word quarts in Illustration 1. This word is embedded into tuple 6. If a similar situation is encountered for all occurrences of quarts in the training corpus, then no translation probability for an independent occurrence of this word will exist. To overcome this problem, the tuple $n$-gram model is enhanced by incorporating 1 -gram translation probabilities for all the embedded words detected during the tuple extraction step. These 1-gram translation probabilities are computed from the intersection of both the source-totarget and the target-to-source alignments. 


\subsection{Additional feature functions}

Apart from the translation model, state-of-the-art systems include several component models are introduced in the maximum entropy approach: typically the target language model and the word bonus. For the Catalan-Spanish language pair, curiously, it is seen that the target language model does not help improving the translation quality (de Gispert and Mariño 2006). However, the POS target language model, which introduces linguistic knowledge (Crego et al. 2006), may help. This POS target language model has to be combined together with the word bonus model for each produced target word, which compensates for the POS target language model preference for short sentences.

\section{Error analysis of the baseline N-II system}

The linguistic error analysis of the baseline N-II system was performed by analyzing, according to the standards of the Institute of Catalan Studies ${ }^{2}$ and the Royal Spanish Academy, ${ }^{3}$ several press articles from the digitalized version of the following newspapers: El Periódico ${ }^{4}$ (in both Spanish and Catalan), La Vanguardia ${ }^{5}$ (Spanish), Avui ${ }^{6}$ and $\mathrm{El} \mathrm{Punt}^{7}$ (Catalan). Since it is well-known that the same sentence can be translated in many different ways, the following criterion was applied in order to decide whether a sentence was correct or not: all the translations achieved can be considered as correct if they maintain the meaning of the original sentence and are grammatically correct.

The main errors found in the translation system were classified according to their corresponding linguistic level: orthographic, morphological, lexical, semantic, and syntactic. Below, the specific problems are described and exemplified in detail and summarized in Table 2, which specifies the direction of translation where the errors are found: Catalan to Spanish (ca2es), Spanish to Catalan (es2ca) or both.

\subsection{Orthographic errors}

\subsubsection{Geminated l (l-l)}

The geminated 1 is one of the characteristics of Catalan that differentiates it from the other Romanic languages. The correct way of writing this grapheme involves use of the middle dot (.); however, the incorrect use of the normal dot (.) is quite widespread among users. The system translates correctly the words containing a geminated $l(l \cdot l)$ provided that they are well-written-i.e. using the middle dot.

\footnotetext{
2 http://www.iec.cat.

3 http://www.rae.es.

${ }^{4}$ http://www.elperiodico.com.

5 http://www.lavanguardia.es.

${ }^{6}$ http://www.avui.cat.

${ }^{7}$ http://www.vilaweb.cat/www/elpunt.
} 
Table 2 Error classification and their corresponding direction of translation

\begin{tabular}{|c|c|c|c|c|}
\hline Level & Error type & Specific problem & ca2es & es $2 \mathrm{ca}$ \\
\hline \multirow[t]{3}{*}{ Orthography } & & Geminated $l$ & $x$ & \\
\hline & & Apostrophe & & $x$ \\
\hline & & y/o conjunctions & $x$ & \\
\hline Morphology & Concordance & Gender concordance & $x$ & $x$ \\
\hline \multirow[t]{3}{*}{ Lexicon } & Unknown words & Capital letters & $x$ & $x$ \\
\hline & & Numbers & $x$ & $x$ \\
\hline & Expression & Time & $x$ & $x$ \\
\hline \multirow[t]{4}{*}{ Semantics } & Polysemy & perquè & $x$ & \\
\hline & Homonymy & Solo & & $x$ \\
\hline & & Soler & $x$ & \\
\hline & & Possessives & $x$ & \\
\hline \multirow[t]{4}{*}{ Syntax } & Pronouns & Clitics & $\times$ & $x$ \\
\hline & & Сиyo & $x$ & $x$ \\
\hline & Verbal periphrasis & Obligation & & $x$ \\
\hline & Prepositions & Elision $d e$ & & $x$ \\
\hline
\end{tabular}

Otherwise, the tokenization process is not performed properly, and erroneous translations are generated. An example related to this kind of error from Catalan into Spanish is illustrated below, where the asterisk symbol (*) refers to the wrong translation.

CA: Aquesta normativa acaba de ser reformada a Brussel.les per liberalitzar la presència de publicitat de la televisió encara més del que ho està.

ES: Esta normativa acaba de ser reformada en *Bruselas. las para liberalizar la presencia de publicidad en televisión aún más de lo que está.

EN: These rules have been reformed in Brussels in order to liberalize still more the advertisements on TV.

\subsubsection{Apostrophe}

The apostrophe is used in Catalan to elide a sound. The singular articles $(e l, l a)$, the preposition $d e$ and some pronouns are apostrophized in front of words beginning with a vowel or an $h$ plus a vowel, though there are some exceptions. In some cases, the baseline N-II does not apostrophize some of the words that should be apostrophized:

ES: 'Cuando se acepta una defensa, la acepta hasta el final', dijo Plaza.

CA: 'Quan s'accepta una defensa, *la accepta fins al final', va dir Plaza.

EN: When a defense is accepted, it is accepted until the end', said Plaza. 
And some words are apostrophized when they should not be:

ES: Ante una situación tan dramática, los mandos del Luz del Mar y Conde de Gondomar lanzaron un SOS a todos los barcos que pudieran navegar en la zona.

CA: Davant d'una situació tan dramàtica, els comandaments *del l'Llum de Mar i Conde de Gondomar van llançar us SOS a tots els vaixells que poguessin navegar a la zona.

EN: In view of such a dramatic situation, the command of Luz del Mar and Conde de Gondomar launched an SOS to all those ships that could be sailing in the area.

\subsubsection{Coordinating conjunctions y and o}

The Spanish coordinating conjunctions $y$ and $o$ change to $e$ and $u$ when they precede words starting by $i$ or $o$ (or $h i$ or ho), respectively. The baseline N-II system usually fails to perform such conversions, leading to an incorrect use of the conjunctions:

CA: Que en alguns casos, com Blanes o Olot, s'estenen interanualment.

ES: Que en algunos casos, como Blanes *o Olot, se extienden interanualmente.

EN: That in some cases, such as Blanes or Olot, they are extended interannually.

\subsection{Morphological errors}

\subsubsection{Lack of gender concordance}

Some words are given a different gender in Catalan and Spanish languages. For instance, the word signal is feminine in Spanish (la señal) and masculine in Catalan (el senyal). Therefore, it is common to find a lack of gender concordance in articles and adjectives with a noun that changes its gender from one language to the other:

CA: Ali tornarà a recuperar no només les cames i la mà, sinó també el somriure.

ES: Ali recuperarà de nuevo no solo las piernas y la mano, sino también *el sonrisa.

EN: Ali will recover again; not only his legs and hand, but also his smile.

This lack of concordance affects also the Spanish-Catalan translation of some invariant possessives such as mi, mis (my), tu, tus (your), etc. 


\subsection{Lexical errors}

\subsubsection{Capital letters and numbers}

Other cases related to unknown words can be found at the lexical level; for instance, in numbers and words that appear only in capital letters in the training corpus. In this case, they will be recognized with capital letters:

CA: Assisteixes a tres actes consecutius.

ES: Asistes a tres actos consecutivos.

EN: You are attending three acts in a row.

and not recognized when written in lower case:

CA: No entenc per què no hi assisteixes.

ES: No entiendo por qué no *assisteixes.

EN: I don't understand why you are not attending to it.

\subsubsection{Time}

In general, time expressions in Spanish and Catalan differ considerably. The main difference is found in the use of the quarters: while in Spanish the time is expressed through the quarters that pass a specific hour, Catalan talks about the quarters that are approaching a specific hour. E.g.:

ES (4:15 h): Las cuatro y cuarto. (Literally: 'four and a quarter').

CA (4:15 h): Un quart de cinc. (Literally: 'a quarter of five').

EN (4:15 h): It's a quarter past four.

These differences in the time expression lead to erroneous translations in the baseline N-II system:

CA (7:45 h): Són tres quarts de vuit.

ES (7:45 h): Son * tres cuartos de ocho.

EN (7:45 h): It's a quarter to eight.

\subsection{Semantic errors}

\subsubsection{The perquè final/causal conjunction}

The conjunction perquè in Catalan is a polysemy-related case. When used to introduce a causal clause, it must be translated into porque (because). However, when it introduces a final subordinate clause, the meaning changes, and it should be 
translated into para que (in order to). Nevertheless, the baseline N-II system usually translates this conjunction into porque, irrespective of its meaning:

CA: Els agents van reduir al conductor per evitar que els fes explotar en cas de portar un detonador portàtil, $i$ van reclamar un equip d'artificiers perquè els desactivessin.

ES: Los agentes redujeron al conductor para evitar que les hiciera explotar en caso de llevar un detonador portátil, y reclamaron un equipo de artificieros *porque los desactivessin.

EN: The agents subdued the driver in order to prevent the explosion in case he had brought a portable detonator, and they called for bomb disposal experts in order to deactivate them.

\subsubsection{Solo adverb/adjective}

In Spanish, solo can be both an adjective and an adverb. Irrespective of its grammatical function, it must be used without a written accent, unless a possible semantic confusion exists. In this case, the adverb must be accented. However, the training corpus does not always follow this rule: the adverb is usually accented, even when it is not necessary. Therefore, the non-accented solo is usually translated as if it was an adjective:

ES: Porque se quiera o no-y más en estos tiempos-, solo cuentan los que siguen vivos y no los que caen por descalificación o accidente.

CA: Perquè es vulgui o no-i més en aquests temps_, *sol compten els que continuen vius $i$ no els que cauen per desqualificació o accident.

EN: Because like it or not-especially in the current days-only those who are still alive and not falling for disqualification or injury count.

\subsubsection{The verb soler}

Another homonymy-related case is found in the verb soler (to be used to). Usually, $\mathrm{N}$-II translates the Catalan verb sols or sol (corresponding to the 2nd and 3rd singular persons of present tense in indicative mood, respectively, of the verb soler), into the Spanish adjectives solos and solo (alone), instead of the corresponding verb conjugations sueles and suele:

CA: La Creu Roja sol disposar de quatre lliteres per atendre els immigrants que arriben en piragua al port de los Cristianos, però ahir n'hi tenia vuit.

ES: La Cruz Roja *solo disponer de cuatro literas para atender a los inmigrantes que llegan en piragua en el puerto de los Cristianos, pero ayer tenía ocho.

EN: The Red Cross usually has four bunk beds to attend to immigrants arriving by canoe at the port of Los Cristianos, but yesterday it had eight. 


\subsubsection{Possessive pronouns and adjectives}

A systematic error was observed in translations between possessive pronouns from Catalan to Spanish: the possessive pronouns meu (mine), tеu (yours), seu (his/hers), etc. are translated as the possessive pronouns $m i$ (my), tu (your), $s u$ (his/her), respectively, instead of mío, tuyo, suyo, etc., as it should be:

ES: No és fàcil portar la pàtria a escena perquè cadascú té la seva.

CA: No es fácil llevar la patria a escena porque cada uno tiene *su.

EN: It is not easy to bring the homeland on stage because everyone has their own.

\subsection{Syntactic errors}

\subsubsection{Pronominal clitics}

Usually, the pronominal clitics lead to translation errors in both Catalan-to-Spanish and Spanish-to-Catalan directions. The most frequent errors are due to an erroneous combination with the corresponding verb:

ES: No quiero verte más por aquí.

CA: No vull veure *et més per aquí.

EN: I don't want to see you here anymore.

or the elision of the pronoun in the target language:

ES: Desde la operación el pequeño se mueve arrastrándose por el suelo.

CA: Des de l'operació el nen es mou arrossegant *[] per terra.

EN: Since he underwent surgery, the little one crawls on the floor.

\subsubsection{The relative pronoun cuyo}

The translation of Spanish relative pronoun cuyo (whose) involves a reordering of elements when it is to be translated into Catalan:

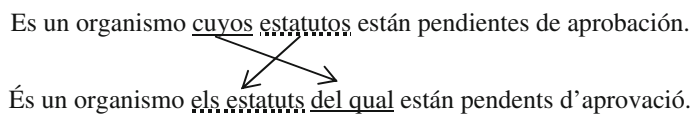

If this reordering is not considered, the N-II will lead to erroneous translations:

ES: Es un organismo cuyos estatutos están pendientes de aprobación.

CA: És un organisme *que té els seus estatuts *están pendents d'aprovació.

EN: It is an organism whose statutes are pending approval. 


\subsubsection{Obligation}

The obligation in Catalan and in Spanish are expressed in different way: where Spanish uses the verb tener que (to must) + infinitive, Catalan utilizes the form haver de + infinitive. The verbal periphrasis tenir que + infinitive, which is not correct, is usually obtained in the Spanish-Catalan translation:

ES: Nos los tenemos que creer, es lo único que nos falta.

CA: Ens ho *tenim que creure, és l'únic que ens falta.

EN: We must believe it, it is the only thing we need.

\subsubsection{Elision/insertion of the preposition de}

It has been seen previously that the verbal periphrasis tener que was translated as tenir que instead of haver de. However, when translating the Spanish form deber, which has the same meaning, the correct expression, haver de, is obtained, but the preposition $d e$ is usually missing:

ES: Las islas Británicas (...) están teniendo unos meses de junio y julio extraordinariamente lluviosos y frescos por la continua entrada de borrascas atlánticas que, por estas fechas, deberían discurrir por latitudes mayores.

CA: Les illes Britàniques (...) estan tenint uns mesos de juny i juliol extraordinàriament plujosos i frescos per la contínua entrada de borrasques atlàntiques que, per aquestes dates, * haurien [] transcórrer per latituds més altes.

EN: The British Isles (...) are having unusually rainy and cool June and July months due to the continuous income of Atlantic squalls which, by these days, should be running at higher latitudes.

Moreover, the preposition de is also elided when translating desde (from, since) into Catalan, obtaining des instead of des de:

ES: Desde el neolítico hasta la actualidad hemos modificado profundamente las plantas y los animales silvestres.

CA: *Des [] el període del neolític fins a l'actualitat hem modificat profundament les plantes $i$ els animals silvestres.

EN: Since the Neolithic Age era until now we have strongly modified the plants and wildlife.

On the other hand, the preposition de falls in front of the conjunction que in Catalan, and this is normally not taken into account by the translator:

ES: Tenías que acordarte de que hoy era el día.

CA: Havies de recordar-te *de que avui era el día.

EN: You should have remembered that today was the day. 


\section{Proposed solutions}

To resolve the errors described in the previous section, several techniques need to be applied according to the idiosyncrasy of the problem. These can be classified into several types: direct text processing-which will be mainly used to solve orthographic errors - as well as the use of rules based on grammatical categories, the statistical model and word categorization. Below, we present a detailed description of such techniques and the errors they can solve.

\subsection{Text edition}

Some of the errors need to be solved by processing the text before or after the translation. The geminated $l$, for instance, was corrected before translation by normalizing the writing of the middle dot. Other cases, such as the obligation tener $q u e$ and the conjunctions $y$ and $o$, have been corrected through post-processing after the translation. Some examples of correction by text edition can be found in Table 3 .

\subsection{Grammatical category-based approach}

Grammatical categories have been successfully used in statistical translation in order to deal with several problems like reordering (Crego and Mariño 2007) and automatic error analysis (Popović et al. 2006). The aim is to add the grammatical category, via a tag, corresponding to the word to translate, so that the statistical model is capable of distinguishing the word depending on its category and to learn from context.

In the current improved system, the grammatical category was provided by the Freeling tool (Carreras et al. 2004), and this information was then used to solve some of the problems found in the baseline system. The grammatical category can be used either in pre-or post-processing rules, or in the translation model as a decoder-based solution. While the former includes solutions for apostrophes, clitics, capital letters at the beginnings of sentences, the relative pronoun cuyo and polysemy disambiguation, the latter becomes useful for the homonymy disambiguation and the lack of gender concordance. A detailed description of the problems solved by this grammatical category-based approach is presented below.

Table 3 Examples of text edition correction

\begin{tabular}{ll}
\hline Geminated l & (S) S'ha reformat a Brussel.les. (It has been reformed in Brussels) \\
& (T1) Se ha reformado en *Bruselas. las \\
& (T2) Se ha reformado en Bruselas \\
Obligation & (S) Nos lo tenemos que creer. (We have to believe it) \\
& (T1) Ens ho *tenim que creure \\
& (T2) Ens ho hem de creure \\
Conjunctions y/o & (S) Que en alguns casos, com Blanes o Olot, s'estenen interanualment \\
& (T1) Que en algunos casos, como Blanes *o Olot, se extienden interanualmente \\
& (T2) Que en algunos casos, como Blanes u Olot, se extienden interanualmente
\end{tabular}




\subsubsection{Apostrophe}

Use of the apostrophe in Catalan relies mostly on basic rules in which the article $e l$, $l a$ and the preposition $d e$ are elided when preceding words that begin with a vowel or a silent $h$ :

$\begin{array}{ll}\text { el arbre } & \text { l'arbre (the tree) } \\ \text { la hora } & \text { l'hora (the time) } \\ \text { de eines } & \text { d'eines (of tools) }\end{array}$

Nevertheless, there are a considerable number of exceptions related to these rules, for instance:

\begin{tabular}{|c|c|}
\hline Exception rule & Example \\
\hline $\begin{array}{l}\text { 1. } e l, l a \text { and } d e \text { when preceding words beginning } \\
\text { with a semiconsonantic vowel }\end{array}$ & $\begin{array}{l}\text { el uombat (the wombat), la hiena (the hyena), } \\
\text { de iogurt (of yogurt) }\end{array}$ \\
\hline $\begin{array}{l}\text { 2. } l a \text { in front of words beginning with } \\
\text { unstressed vowels } i \text { and } u\end{array}$ & la universitat (the university), la Irene (Irene) \\
\hline 3. $l a$ and $d e$ in front of the negative prefix $a$ & $\begin{array}{l}\text { la anormalitat (the anormality), de asimètric } \\
\text { (of asimetric) }\end{array}$ \\
\hline 4. Names of letters & la $e$, la erra, la hac, etc. (the e, the $\mathrm{r}$, the $\mathrm{h}$ ) \\
\hline 5. Exception words & $\begin{array}{l}\text { la una (one o'clock), la ira (the wrath), } \\
\text { la host (the host) }\end{array}$ \\
\hline
\end{tabular}

\subsubsection{Pronominal clitics}

Pronominal clitics are first detected by using the Freeling tool and are separated from the corresponding verb. Then, the isolated pronominal clitic is translated and, finally, a rules-based text correction is performed as a post-processing of the translation. These correction rules consider the following factors:

1. The Spanish accentuation rules, since the position of the stressed syllable changes when adding an enclitic pronoun to the verb:

$$
\text { vende }+ \text { lo véndelo (sell it) }
$$

2. The combination of the Catalan pronouns, which, unlike Spanish pronouns, use hyphens or apostrophes, but the accentuation rules are not altered. 


$\begin{array}{ll}\text { seguir+lo } & \text { seguir-lo (follow it) } \\ \text { la hora } & \text { compra'l (buy it) } \\ \text { de eines } & \text { d'eines (of tools) } \\ \text { el+aixecava } & \text { l'aixecava (lifted it) }\end{array}$

Some examples of clitics and apostrophe correction can be found in Table 4.

\subsubsection{Capital letters at the beginning of the sentence}

To solve one of the causes of unknown words, a technique that uses morphological information is used: all the words that can be found at the sentence beginning are changed into lower case words, except for common and proper nouns and adjectives, which tend also to be proper nouns and are usually not found at the beginning of sentences. Therefore, all those words that were found with capital letters in the training corpus will no longer seem to be unknown words when lower case letters are used during translation. Table 5 shows an example in which, given a source sentence $(\mathrm{S})$, we see the corresponding translations before (T1) and after (T2) applying the capital letters processing.

\subsubsection{Cuyo pronoun}

Problems related to the relative pronoun cuyo mainly arise because few sentences including this pronoun are contained in the training corpus, and so the system is not able to learn the specific structure properly. To solve this problem, a preprocessing rule was applied to transform the Spanish structure into a literal translation of the

Table 4 Examples of clitics and apostrophe correction

\begin{tabular}{ll}
\hline Clitics & (S) No quiero verte más por aquí. (I don't want to see you here anymore) \\
& (T1) No vull veure *et més per aquí \\
& (T2) No vull veure't més per aquí \\
Apostrophe & (S) La acepta hasta el final. (He accepts it until the end) \\
& (T1) *La accepta fins al final \\
& (T2) L'accepta fins al final \\
\hline
\end{tabular}

Table 5 Examples of translation before and after applying capital letters processing and 'cuyo' correction

\begin{tabular}{ll}
\hline Capital letters & (S) No entenc per què no hi assisteixes \\
& (T1) No entiendo por qué no *assisteixes \\
& (T2) No entiendo por qué no asistes \\
Cuyo & (S) Un pueblo cuyo nombre es largo. (A village whose name is long) \\
& (T1) Un poble *amb un nom és llarg \\
& (T2) Un poble el nom del qual és llarg \\
\hline
\end{tabular}


Catalan structure del qual; in other words, the sentences containing cuyo or some of its other forms (cuya, cuyos, cuyas) were transformed into sentences containing del cual or its corresponding forms (de la cual, de los cuales, de las cuales), so that alignment was easier. Some translation errors related to this pronoun were avoided in this way (see Table 5).

A similar process was then performed in the inverse direction-Catalan-toSpanish-as a post-processing procedure: when the Catalan grammatical structure that corresponds to the Spanish structure that makes uses of cuyo is found, del qual is translated into cuyo, and the proper word reordering is performed. Otherwise, it is literally translated into del cual.

\subsubsection{Polysemy disambiguation}

As noted in the previous section, the conjunction perquè is translated into para que when followed by a final subordinate clause, which is expressed by a verb in the subjunctive mood. Thus, when a verb in the subjunctive is detected after the conjunction perquè-even if there are other words in between-the translation into Spanish will be para que. In the same way, another rule will fix errors that occur if the verb is expressed in the indicative mood, so that the translation will be porque. Table 6 shows an example of correcting the use of this conjunction.

This rule is not $100 \%$ fulfilled, since it is possible to find a verb in the indicative which is preceded by the conjunction porque. However, an estimation made from the training corpus showed that this structure is found in less than the $0.5 \%$ of the cases in which the conjunction porque appears.

\subsubsection{Homonymy disambiguation}

In the translation task, it is quite common to find two words spelled the same in the source language that differ in the target language. When both words are

Table 6 Examples of correction after homonymy and polysemy disambiguation

\begin{tabular}{ll}
\hline Perquè & (S) T'ho pregunto perquè m'ho diguis \\
& (T1) Te lo pregunto *porque me lo digas \\
& (T2) Te lo pregunto para que me lo digas \\
Soler & (S) La Creu Roja sol disposar de quatre lliteres \\
& (T1) La Cruz Roja *solo disponer de cuatro literas \\
& (T2) La Cruz Roja suele disponer de cuatro literas \\
Solo & (S) Era solo un niño \\
& (T1) Era *sol un nen \\
& (T2) Només era un nen \\
Possessives & (S) Els meus amics no són els teus \\
& (T1) Mis amigos no están *tus \\
& (T2) Mis amigos no son los tuyos
\end{tabular}


homonymous and they are characterized by a different grammatical category, such a category will be useful to disambiguate their meaning. The verb soler, the adjective/ adverb solo and the possessives are examples of homonymous words that lead to problematic ambiguity. In some cases, the tag given by Freeling is simply added to the homonymous words to disambiguate them. In other cases, the output tag given by Freeling is not correct-as in the case of the adjective/adverb solo and the possessives - so it becomes necessary to establish a set of rules that will provide the correct tag. This set of rules is described below.

5.2.6.1 The verb soler In order to disambiguate the homonymous words sol and sols, the corresponding adjective or verb tag given by the Freeling was added to the words in question.

5.2.6.2 The solo case In order to solve the solo problem, the following rules were implemented in order to identify, in doubtful cases, whether the solo term was an adverb or an adjective, since the Freeling tool would output erroneous tags.

\begin{tabular}{|c|c|c|}
\hline Category & Context & Example \\
\hline \multirow[t]{3}{*}{ Adjective } & $\begin{array}{l}\text { At the beginning of a sentence or } \\
\text { after a semicolon, followed by } \\
\text { conjunction or comma }\end{array}$ & $\begin{array}{l}\text { Solo, cansado y desesperado, se } \\
\text { marchó. (Alone, tired and } \\
\text { desperate, he left). }\end{array}$ \\
\hline & $\begin{array}{l}\text { When followed by one of these } \\
\text { punctuation marks:.,;!? "() - }\end{array}$ & Estoy solo. (I am alone). \\
\hline & Before the conjunctions $y$ or $o$ & $\begin{array}{l}\text { Estaba solo y triste. (He was alone } \\
\text { and sad). }\end{array}$ \\
\hline \multirow[t]{5}{*}{ Adverb } & $\begin{array}{l}\text { At the beginning of a sentence or } \\
\text { after a semicolon and not followed } \\
\text { by a conjunction or comma }\end{array}$ & $\begin{array}{l}\text { Solo quiero manzanas. (I just want } \\
\text { apples). }\end{array}$ \\
\hline & $\begin{array}{l}\text { After the verbs ser and haber, } \\
\text { followed optionally by the adverb } \\
\text { tan }\end{array}$ & $\begin{array}{l}\text { Esto es (tan) solo es principio del } \\
\text { partido. (This is just the beginning } \\
\text { of the match). }\end{array}$ \\
\hline & After a preposition & $\begin{array}{l}\text { Se ha producido a solo tres meses de } \\
\text { los Juegos Olímpicos. (It happened } \\
\text { only three months before the } \\
\text { Olympic Games) }\end{array}$ \\
\hline & $\begin{array}{l}\text { At the beginning of a sentence } \\
\text { and followed by a verb }\end{array}$ & $\begin{array}{l}\text { Solo quiero escuchar un poco de } \\
\text { música. (I only want to listen to } \\
\text { some music). }\end{array}$ \\
\hline & $\begin{array}{l}\text { After a verb with which there } \\
\text { is no number concordance }\end{array}$ & $\begin{array}{l}\text { Vinieron solo para comer. (They } \\
\text { came only for lunch). }\end{array}$ \\
\hline
\end{tabular}


These rules were then applied to the source language and the corresponding tag was added to the word. Thus, a source sentence like Venía solo (he was coming alone) was changed to Venía solo_<ADJ>, and this allowed the model to distinguish both possibilities and to learn from context.

5.2.6.3 Possessives A similar task was performed on Catalan possessive adjectives and pronouns. A set of rules (listed below) was designed in order to tag a specific word as an adjective or pronoun. These tags are then added to the Catalan corpus.

\begin{tabular}{lcc}
\hline Category & Context & Example \\
\hline $\begin{array}{l}\text { Adjective } \\
\text { Pronoun }\end{array}$ & Before noun or adjective & $\begin{array}{l}\text { El meu cotxe. (My car). } \\
\text { Aquest cotxe és meu. } \\
\text { (This car is mine). }\end{array}$ \\
\hline
\end{tabular}

Table 6 shows some examples of correction by using homonymy disambiguation in the three cases described in this section: soler, solo and possessives. Given a source sentence (S), the resulting translations before (T1) and after (T2) applying the obtained tags are shown. The errors produced in $\mathrm{T} 1$ are solved in $\mathrm{T} 2$.

\subsubsection{Gender concordance}

The problem of gender concordance is solved by using a POS language model in the target language. This allows us to assign higher value to those word sequences that maintain gender coherence; therefore, the likelihood of a sequence like pilota_FN vermella_FAdj (where FN is a feminine noun and FAdj a feminine adjective) will be higher than pilota_FN vermell_MAdj (where MAdj is a masculine adjective), since the POS language model will have seen the sequence FN-FAdj more times than the sequence FN-MAdj (see an example of correction in Table 7). Nevertheless, the POS language model will be useful only if the bilingual unit exists. Thus, the translation of senyal_MN blanc_MAdj will remain as señal_FN blanco_MAdj instead of señal_FN blanca_FAdj, since the tuple blanc\#blanca is not contained in the translation model.

Remember that the POS language model requires the introduction of the word bonus feature to compensate for short outputs. To optimize the POS language model and the word bonus with the minimum error rate procedure (Och 2003), a specific development corpus was created. This development corpus, which consists of 476 sentences and one reference, was manually created to ensure that the corpus was grammatically correct and that it contained all the problems we had encountered.

Table 7 Examples of gender concordance

\begin{tabular}{ll}
\hline Gender & (S) Me encantan las espinacas. (I love spinachs) \\
& (T1) M'encanten *les espinacs. \\
& (T2) M'encanten els espinacs.
\end{tabular}


Given that we have tuned these features on a special corpus, we consider them as part of the improved system. Therefore, notice that the baseline system as in previous Catalan-Spanish works (de Gispert and Mariño 2006) does only include the translation model.

\subsection{Numbers and time categorization}

\subsubsection{Numbers}

As shown in the previous section, some numbers that were not in the training corpus might appear in the source sentence to be translated, so such numbers are marked as unknown and thus not translated. To avoid this problem, a set of rules was implemented to detect the numbers in the source language-except for un/una (one), dos/dues (two), nou (nine) and deu (ten), which can also correspond to other terms than numbers-and then to codify and generate them in the target language.

In order to detect the numbers, it is necessary to consider their formal structurei.e. whether the number is a compound noun, using or not using dashes, etc. It is also necessary to take into account that numeral adjectives can have an associated gender. A specific codification is thus defined so that, in the generation process, the final number is coherent with the detected number. For instance, the numeral adjective quaranta-una would have the corresponding codification:

$$
\mathrm{Z}|41| \mathrm{F}|2| \mathrm{Z}
$$

The first and last fields $(\mathrm{Z})$ indicate a numerical expression. The second, third and fourth fields indicate: the numerical expression in figures, a feminine adjective, and the number of words replaced in the codification, respectively. The feminine mark is used to establish gender coherence with the following term.

\subsubsection{Time}

Catalan time expression is formally different from that in Spanish, as discussed above. Since the corpus contains few examples related to time expressions, time translation errors were frequent. In order to solve this problem, the same procedure performed with the numbers is performed here: the time expressions are detected, codified, and generated again in the target language.

Time expressions are identified using three different structures, following the most formal notations presented by J. M. Mestres $(2004)^{8}$ : the precise international notation, the formal general notation, and the mixed formal notation. In the Catalan to Spanish case, only the third one was activated, since the other ones can be literally translated between these pair of languages and do not need any special codification. However, the code was thought for all the notations in order to be able to be used in other language pairs.

The codification is performed by using a ten-field code, where the first and the last fields express the fact that we are dealing with a time expression (HORA). Thus,

\footnotetext{
${ }^{8}$ http://www.comunicaciodigital.com/rellotge_catala/pdf/notacions_horaries.pdf.
} 
the time phrase it's $4.45 \mathrm{pm}$, expressed in Catalan as Són tres quarts de cinc de la tarda, would be codified as follows:

$$
\text { HORA }|4| \varnothing|45| \varnothing|\mathrm{C}| \mathrm{T}|8| \mathrm{S} \mid \text { HORA }
$$

where the inside fields express the following:

$\begin{array}{ll}4 & \text { Numerical hour } \\ \varnothing & \text { The term hores (hours) is not included } \\ 45 & \text { Numerical minutes } \\ \varnothing & \text { The term minuts (minutes) is not included } \\ \mathrm{C} & \text { Type of time notation (mixed formal) } \\ \mathrm{T} & \text { Timeslot: tarda (afternoon) } \\ 8 & \text { Number of words replaced in the codification } \\ \mathrm{S} & \text { The verb ser (to be) is included }\end{array}$

Table 8 shows an example in which, given a source sentence (S) with an unknown numerical expression leading to a non-correct translation (T1), the translation is corrected (T2) by applying the corresponding categorization. Examples for time expressions are also included.

Table 9 summarizes the errors encountered in this study and classified according to the type of solution proposed for overcoming them.

\section{Evaluation}

The SMT scientific community tends to agree on using the BLEU automatic measure to evaluate improvement in a translation system. Additionally, human evaluation is used when enough resources are available.

In this study, we introduced linguistic knowledge into an SMT system, mainly by using linguistic rules in order to improve a baseline system. Both automatic and human evaluations were used in the final system in order to make the final evaluation complete and objective. The baseline system-an N-gram-based SMT system without linguistic information and only including the translation model as in previous Catalan-Spanish works (de Gispert and Mariño 2006)—was thus compared with the same system after adding the improvements described in this paper.

\subsection{Test corpora}

The Spanish source test corpus consists of 711 sentences extracted from El País and La Vanguardia, while the Catalan source test corpus consists of 813 sentences extracted from the Avui newspaper and from transcriptions from the TV program Àgora. Each direction set contains two manual references. Table 10 shows the statistics on the number of sentences, words and vocabulary for each language. 
Table 8 Examples of correction after the number and time categorization

\begin{tabular}{ll}
\hline Numbers & (S) L'alliberament de quatre-cents quaranta-un \\
presoners. (The liberation of four hundred \\
and forty-four prisoners) \\
(T1) La liberación de *quatre-cents quaranta-un \\
prisioneros \\
(T2) La liberación de cuatrocientos cuarenta y un \\
prisioneros \\
(S) Són tres quarts de vuit. (It's a quarter to eight) \\
Time \\
(T1) Son *tres cuartos de ocho \\
(T2) Son las ocho menos cuarto
\end{tabular}

Table 9 Errors treated by types of solution

\begin{tabular}{lllll}
\hline Error & Text edition & \multicolumn{2}{l}{ Grammatical information } & Categorization \\
\cline { 3 - 4 } & & Pre-/postprocess & Translation model & \\
\hline $\begin{array}{l}\text { Geminated 'l' } \\
\text { Apostrophe }\end{array}$ & $\times$ & $\times$ & & \\
y/o conjunctions & $\times$ & & & \\
Gender concordance & & $\times$ & & \\
Capital letters & & & & \\
Numbers & & $\times$ & & \\
Time & & & $\times$ & \\
Perquè & & & $\times$ & \\
Solo & & $\times$ & & \\
Soler & & $\times$ & & \\
Clitics & & & & \\
Cuyo & & & & \\
Possessives & & & & \\
Obligation & $\times$ & & & \\
Elisión de & $\times$ & & & \\
\hline
\end{tabular}

\subsection{Human evaluation}

To better analyze the output translations of both systems, a human evaluation is provided. First, the test sentences are classified into different categories according to the errors that were outlined in the error analysis section. This classification allowed us directly to compare the success of the specific techniques used to solve the corresponding problem. Second, a generic comparison was performed in order to evaluate how much better the improved system was, in general terms, with respect to the baseline system. 
Table 10 Test corpora statistics

\begin{tabular}{llll}
\hline & Sentences & Words & Vocabulary \\
\hline Spanish & 711 & 15,974 & 5,702 \\
Catalan & 813 & 17,099 & 5,540 \\
\hline
\end{tabular}

\subsubsection{Specific evaluation}

Although the proposed solutions were applied to improve detected errors, a specific technique may not be completely successful in solving a problem. Thus, given a specific problem and a specific technique to solve it, the aim here is to know how many cases were

(a) Already correct: baseline outputs that were not modified by the improved system,

(b) Not corrected: baseline outputs that were incorrect and that the improved system could not solve,

(c) Improved: baseline outputs that were incorrect and that the improved system did solve, and

(d) Damaged: baseline outputs that were correct and that the improved system translated incorrectly.

This classification can be seen in Table 11 for both directions of translation, together with the overall percentage of already correct, not corrected, improved and damaged cases. It can clearly be seen that, although most of the cases did not present a problem, a considerable number of cases $(18.9 \%$ in ca2es and $13.9 \%$ in es $2 c a$ ) were initially problematic and solved using the presented techniques.

Thus, the analysis shows that the proposed techniques are useful for handling the detected problems. Regarding clitics, some cases were still not solved, mainly because the decoder chose the wrong pronoun or a different place: l'últim any *ho va passar instead of l'últim any va passar-lo. In this case, for instance, the place is interchangeable, but the wrong pronoun selection results from a case of polysemy, since both pronouns are related to the same source (Spanish) pronoun. The clitics solution takes for granted that the translation is correct and then processes a grammatically correct sequence; if the translation is not correct, the solution is not able to solve the problem.

Since the human evaluation was performed from the journalism corpus, not all the error types were present in the evaluated sentences. This is the reason why not all the analyzed error types are contained in Table 11.

The damaged cases appear for several reasons. Clitics such as estar-se, for instance, were damaged because in some contexts, estar is not recognized as a verb by the tagger. Therefore, the proposed solution damages the baseline system, which was able to learn the correct translation from the training corpus.

In two other situations, translations in the number category were not able to maintain gender concordance, so when a sequence had been seen in the training 


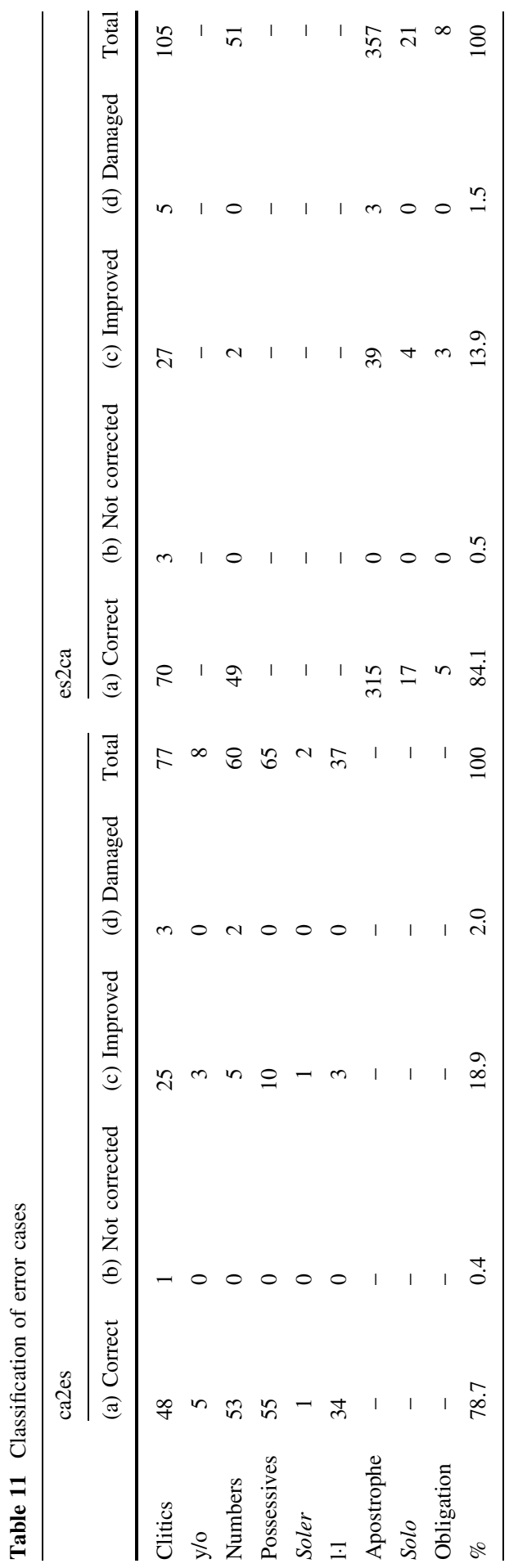


Fig. 1 Percentage of correct cases for both baseline and improved systems in each direction of translation

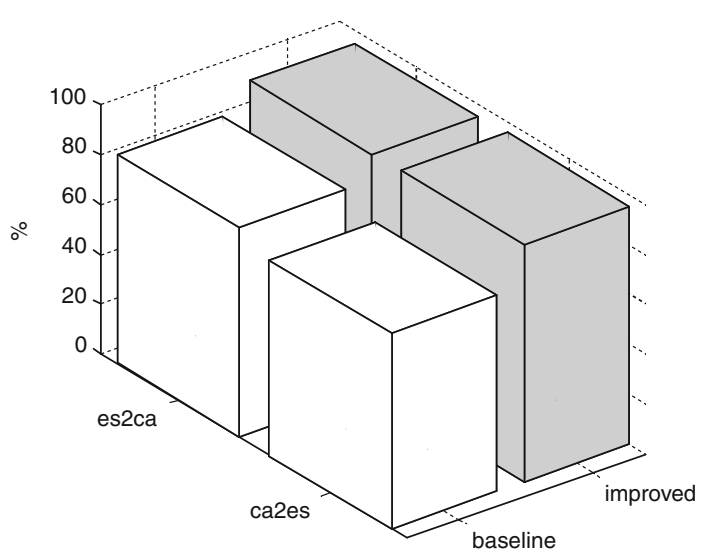

corpus, the translation of numbers was better performed by the baseline than by the improved system. Finally, the solution applied to handle the apostrophe problem did not cover all the exceptions, such as the apostrophe of some Catalan acronyms that do not follow the basic apostrophe rules. This led to damaged cases, for which an additional dictionary would be required to build a proper apostrophe rule.

Figure 1 shows the percentage of correct cases over the total number of problematic cases treated above. The percentage of correct cases increases clearly in both directions of translation: in Catalan to Spanish (es2es) correct cases go from 78.7 to $95.6 \%$, and in the inverse direction (Spanish to Catalan) the percentage increases from 84.2 to $94.6 \%$.

\subsubsection{General evaluation}

Second, a generic comparison of both systems was performed using human criteria. Ten native evaluators made a blind comparison of 200 different sentences randomly selected from each system. Five evaluators are native in Catalan and Spanish and they evaluated Spanish-to-Catalan. Five different evaluators are native in Spanish and they evaluated Catalan-to-Spanish. Score criterion was simple: given the source sentence, they were asked to choose the best translation from the two outputs. Tails were accepted. The results obtained in this evaluation are shown in Table 12, ordered by evaluator and system, and the overall resulting percentages of the results are illustrated in Fig. 2.

\subsection{Automatic evaluation}

The test corpus and two available references were used to compute the BLEU score for the translations provided by the baseline and the improved systems. The results are presented in Table 13. It can clearly be seen that the improved system performs significantly better in terms of BLEU. In the Catalan-to-Spanish direction the gain is 0.47 points BLEU, whereas in the Spanish-to-Catalan translation the improvement 
Table 12 Human evaluation results

\begin{tabular}{|c|c|c|c|c|c|c|c|}
\hline \multicolumn{4}{|c|}{ Catalan to Spanish } & \multicolumn{4}{|c|}{ Spanish to Catalan } \\
\hline Evaluator & Baseline & Improved & Equal & Evaluator & Baseline & Improved & Equal \\
\hline 1 & 10 & 21 & 169 & 6 & 22 & 51 & 127 \\
\hline 2 & 44 & 52 & 104 & 7 & 34 & 52 & 114 \\
\hline 3 & 32 & 35 & 133 & 8 & 31 & 51 & 118 \\
\hline 4 & 35 & 36 & 129 & 9 & 12 & 69 & 119 \\
\hline 5 & 4 & 16 & 180 & 10 & 6 & 31 & 163 \\
\hline$\%$ & 12.5 & 16.0 & 71.5 & $\%$ & 10.5 & 25.4 & 64.1 \\
\hline
\end{tabular}

Fig. 2 Percentage of better and equal cases in the human evaluation

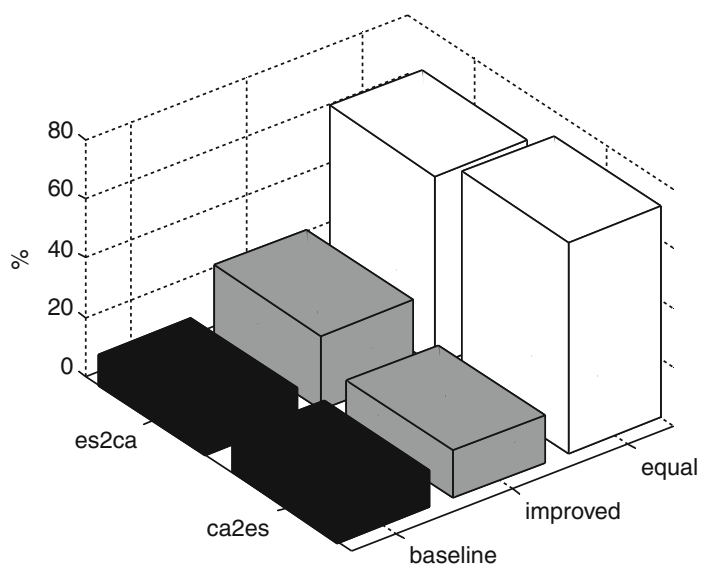

rises to 1.09 points BLEU. The margin of error was calculated with a $90 \%$ Wald confidence interval (Newcombe 1998).

The results show a higher improvement in the Spanish-to-Catalan direction than in the reverse direction. The first reason for such a difference may be that in the Catalan-to-Spanish translation, we are starting from a better baseline system, which is more difficult to outperform. The second reason may be that, as was seen before, the test does not cover many of the problems that were addressed in the present work. To evaluate the improvement of the system when using the specific problems addressed, an ad hoc test was proposed, consisting of 636 sentences for both directions of translation. Each direction set had one manual reference. The number of sentences, words and vocabulary for each language are found in Table 14. This test was built to evaluate exclusively the proposed methods. Therefore, a CatalanSpanish linguist wrote this test set from scratch focusing on the points that we were trying to solve.

Subsequently, a second automatic evaluation was performed with this test, which tried to represent the challenges the present study was trying to overcome, so that it helped to amplify and to better analyze the influence of the proposed solutions. Moreover, unlike the previous corpus, all types of errors were contained in the 
tested sentences. Table 15 shows the results of this evaluation, where the improvement is about 5.5 points BLEU in both directions of translation.

\section{Conclusions and future work}

In this paper, a set of strategies was applied with the aim of overcoming the problems found in a preliminary statistical machine translation between the CatalanSpanish language pair. The translation errors addressed were related to different linguistic dimensions: orthographic, morphological, lexical, semantic and syntactic. The proposed solutions made use of several strategies, such as text processing, grammatical category-based rules, statistical modeling, and word and phrase categorization. These techniques resulted in an improvement of the baseline translation system, especially in the Spanish-to-Catalan direction, where a gain of up to 1.1 points BLEU was obtained. Human evaluation also showed the employed strategies to have a positive effect in both directions of translation, when considering both the specific problems addressed in this work and the overall performance of the system.

Nevertheless, the list of problems to overcome is still not finished, and they have been left for future work. These are, for instance, the verbal forms at the morphological level, and the use of specific prepositions at the syntactic level. The problem associated with verbal forms resides in the fact that only the lemma or other conjugated forms of the verb in question are included in the training corpus, so that the conjugated word is returned as unknown. In the following example, the Spanish first person simple future of the verb to pass is translated, while the second person is output as an unknown word:

Table 13 BLEU results obtained in the baseline and improved systems

Table 14 Ad hoc test corpora statistics

Table 15 BLEU results obtained in the baseline and improved systems

\begin{tabular}{lll}
\hline & $\begin{array}{l}\text { Catalan to } \\
\text { Spanish (ca2es) }\end{array}$ & $\begin{array}{l}\text { Spanish to } \\
\text { Catalan (es2ca) }\end{array}$ \\
\hline Baseline & $86.57 \pm 0.44$ & $84.91 \pm 0.45$ \\
Improved & $87.04 \pm 0.44$ & $86.00 \pm 0.44$ \\
\hline
\end{tabular}

\begin{tabular}{llll}
\hline & Sentences & Words & Vocabulary \\
\hline Spanish & 636 & 6,711 & 2,505 \\
Catalan & 636 & 6,734 & 2,516 \\
\hline
\end{tabular}

\begin{tabular}{lll}
\hline & $\begin{array}{l}\text { Catalan to } \\
\text { Spanish (ca2es) }\end{array}$ & $\begin{array}{l}\text { Spanish to } \\
\text { Catalan (es2ca) }\end{array}$ \\
\hline Baseline & $73.50 \pm 0.89$ & $75.91 \pm 0.86$ \\
Improved & $79.02 \pm 0.82$ & $81.35 \pm 0.78$ \\
\hline
\end{tabular}


ES: ¿Crees que aprobarás la asignatura? Por supuesto que aprobaré.

ES: ¿Creus que *aprobarás l'assignatura? Per descomptat que aprovaré.

EN: Do you think you will pass the exam? Of course I will pass it.

Other common errors are related to the different use of prepositions in both languages. In Catalan, for instance, the preposition $a$ is normally not used in front of a direct object, so this preposition will not appear in the target (Spanish) language when it is, in fact, required:

CA: Va dir que el taxista s'havia alegrat molt quan va agafar el viatger.

ES: Dijo que el taxista se había alegrado mucho cuando cogió *el viajero.

EN: He said that the taxi driver was very happy to take the passenger.

On the other hand, the $a$ and $e n$ prepositions are commonly used in Catalan and Spanish languages to introduce both special and temporal elements. However, they are used in very distinct ways in these two languages, so translation errors are frequently observed in such cases due to these usage differences.

\section{ES: El sábado, en las ocho horas de jornada laboral, solo 30 personas se pusieron en contacto con ella.}

CA: Dissabte, *a les vuit hores de jornada laboral, només 30 persones es van posar en contacte amb ella.

EN: On Saturday, during eight hours of work, only 30 persons contacted her.

Future work should include the detection of additional errors. Polysemy and homonymy, for instance, have been detected in the current work by means of human knowledge. A new challenge would be to generalize homonymous and polysemic errors and to detect them using machine learning techniques. Finally, apart from solving remaining errors, future work should also work to avoid damaged cases: those cases already correct and included in the training corpus should remain unchanged in the translation process.

However, the current work has demonstrated that, despite the list of errors that are still to be solved, the presented N-II system provides high-quality translations between Catalan and Spanish languages and is freely available online as a linguistic resource.

Acknowledgments The authors would like to thank TALP Research Center and Barcelona Media Innovation Center for its support and permission to publish this research. We would like to give credit to the anonymous reviewers of this paper for their valuable suggestions. This work has been partially funded by the Spanish Department of Science and Innovation through the Juan de la Cierva fellowship program and the Spanish Government under the BUCEADOR project (TEC2009-14094-C04-01).

\section{References}

Bangalore, S., \& Riccardi, G. (2000). Stochastic finite-state models for spoken language machine translation. In Workshop on Embedded Machine Translation Systems, Seattle, WA.

Brown, P., della Pietra, S., et al. (1993). The mathematics of statistical machine translation. Computational Linguistics, 19(2), 263-311. 
Carreras, X., Chao, I., et al. (2004). FreeLing: An open-source suite of language analyzers. In Conference on Language Resources and Evaluation, Lisbon, Portugal.

Casacuberta, F., \& Vidal, E. (2004). Machine translation with inferred stochastic finite-state transducers. Computational Linguistics, 30(2), 205-225.

Crego, J. M., de Gispert, A., et al. (2006). N-gram-based SMT System Enhanced with Reordering. In Human Language Technology Conference (HLT-NAACL'06): Proceedings of the Workshop on Statistical Machine Translation, New York.

Crego, J. M., \& Mariño, J. B. (2007). Improving SMT by coupling reordering and decoding. Machine Translation, 20(3), 199-215.

de Gispert, A., \& Mariño, J. (2006). Catalan-English statistical machine translation without parallel corpus: Bridging through Spanish. In Proceedings of LREC 5th Workshop on Strategies for developing Machine Translation for Minority Languages (SALTMIL'06). Genova, 65-68.

Mariño, J. B., Banchs, R. E., et al. (2006). N-gram based machine translation. Computational Linguistics, 32(4), 527-549.

Newcombe, R. G. (1998). Two-sided confidence intervals for the single proportion: Comparison of seven methods. Statistics in Medicine, 17(8), 857-872.

Niessen, S., \& Ney, H. (2000). Improving SMT quality with morpho-syntactic analysis. In International Conference on Computational Linguistics, Saarbrücken, Germany.

Och, F. J. (2003). Minimum error rate training in statistical machine translation. In 41st Meeting of the Association for Computational Linguistics, Sapporo, Japan.

Popović, M., de Gispert, A., et al. (2006). Morpho-syntactic information for automatic error analysis of statistical machine translation output. In HLT/NAACL Workshop on Statistical Machine Translation, New York.

Popović, M., \& Ney, H. (2004). Towards the use of word stems and suffixes for statistical machine translation. In International Conference on Language Resources and Evaluation, Lisbon, Portugal.

Popović, M., \& Ney, H. (2006). POS-based word reorderings for statistical machine translation. In International Conference on Language Resources and Evaluation, Genoa, Italy. 